\title{
Possibilidades de aplicação do conhecimento sobre comportamento humano como subsídio para o aprimoramento da capacitação de administradores de empresas em nível superior*
}

\author{
Posibilidades de aplicación del conocimiento acerca del comportamiento \\ humano como base para el mejoramiento de la capacitación de \\ administradores de empresas en nivel superior
} Possible applications of knowledge on human behavior to the professional
development of college graduate business managers

Carlos Leonardo Rohrbacher ${ }^{1}$, Olga Mitsue Kubo², Sílvio Paulo Botomé ${ }^{3}$

[1] [2] [3] Universidade Federal de Santa Catarina I Título abreviado: Conhecimento sobre Comportamento Humano como Subsídio para Graduação em Administração de Empresas I Endereço para correspondência: Avenida Pres. Epitácio Pessoa, 111, apto 136 - Centro. Jaraguá do Sul - SC CEP 89251100 Email: carlosrohrbacher@hotmail.com

\begin{abstract}
Resumo: Neste estudo, foram avaliadas as informações contidas em planos de ensino de disciplinas de quatro cursos de graduação em Administração de Empresas de um estado do sul do Brasil, de modo que se pudesse aferir a qualidade e a pertinência do que está sendo objeto de ensino do professor em cursos de formação de nível superior quanto ao comportamento humano. Foi identificado que as características das relações entre fenômeno psicológico e fenômeno administrativo nos planos de ensino de cursos de graduação em Administração de Empresas indicam conhecimento insuficiente sobre as possibilidades da contribuição do conhecimento psicológico para o trabalho do administrador de empresas por quem tem a responsabilidade pela sua capacitação. A utilização desse conhecimento parcial pelos administradores de empresas provavelmente produziria comportamentos que não os ajudariam a lidar com comportamento humano em organizações de forma efetiva e eficaz.
\end{abstract}

Palavras-chave: comportamento humano, psicologia, administração de empresas, planos de ensino. 
Abstract: In this study, information of teaching plans from four undergraduate courses of Business and Management of a Southern state of Brazil, in order to ascertain the quality and the relevance of the study objectives regarding human behavior that the teacher proposes as guidelines to the higher education learning process. The study points out that the characteristics of the relations between the psychological phenomenon and the management phenomenon in the teaching plans reveal the business teachers' insufficient knowledge about the possibilities of practical applications of psychological knowledge in the managers' learning processes. The managers' partial use of such knowledge would probably result in behaviors that would not be helpful for managers in order to deal with human behavior in organization effectively and efficiently.

Key words: human behavior, psychology, management, business, teaching plans.

Resumen: El estudio evaluó la información contenida en los planes de estudio de cuatro cursos de licenciatura en Administración de Empresas de un estado del sur del Brasil, de modo a evaluarse la calidad y pertinencia del contenido de enseñanza con respecto a la conducta humana que el profesor presenta en cursos de formación en nivel superior. Se identificó que las características de la relación entre el fenómeno psicológico y el fenómeno administrativo en los planes de estudio de cursos de licenciatura en Administración de Empresas indican un conocimiento insuficiente de los profesores sobre las posibilidades de la contribución de los conocimientos psicológicos para el trabajo del gerente de negocios. El uso de este conocimiento incompleto por gerentes de empresas probablemente no produce comportamientos que ayuden a lidiar con el comportamiento humano en las organizaciones de manera eficaz y eficiente.

Palabras-clave: comportamiento humano, psicología, administración de empresas, planes de enseñanza. 
Apresentar objetivos de ensino é uma tarefa árdua a quem planeja o ensino de alunos em cursos superiores. Para fazê-lo, seria importante que o professor estivesse atento ao que é necessário à comunidade em que o aluno irá se inserir como profissional formado, assim como ao insumo necessário ao aprendizado e aos melhores meios de produzir esses comportamentos-objetivo no aluno de modo que se estabeleçam como repertório útil ao seu futuro profissional. A Psicologia, por ter como fenômeno de estudo e de intervenção o comportamento dos organismos, deve apresentar conhecimentos significativos para profissionais de diversas áreas do conhecimento que necessitam intervir sobre comportamento humano em algum momento de seu trabalho.

\section{O Problema dos Falsos Objetivos de Ensino}

Objetivos de ensino são fundamentais para a educação. Sua definição, planejamento, implementação e avaliação visam garantir que ocorra o aprendizado do aluno. Botomé (1987) descreveu sete tipos de falsos objetivos (ou pseudo-objetivos) de ensino, muito encontrados em organizações de ensino. (a) Itens de conteúdo foi o nome dado ao conjunto de propostas de ensino que têm em comum a metáfora de "transmissão de conteúdos" aos alunos, como se a apresentação de informações fosse fim (o que pessoa deve fazer com ou a partir das informações) e não um dos meios de ensinar. (b) Declarações de intenções de professores indica o que o professor pretende fazer geralmente de forma vaga e genérica, similar ao que é concebido como "missão" em muitas organizações. A declaração vaga e grandiosa possibilita que, mesmo que o professor não atinja o objetivo (se é que há como avaliar aprendizado de objetivos imprecisos), ele possa ser avaliado como alguém que ao menos teve uma "boa intenção". (c) Atividades dos professores, assim como as informações, não são finalidade, mas meio de produzir aprendizado no aluno. Sabendo o que o professor irá fazer é importante perguntar quais os resultados que serão produzidos. "Apresentar dinâmicas em aulas expositivas" e "levar alunos a visitas a organizações" são exemplos de atividades centradas em ações do professor sem a contrapartida do aluno; caso o aluno não aprenda, pode ser culpado pelo próprio fracasso. $\mathrm{O}$ aluno pode ser avaliado como "desmotivado", "não engajado" e etc. Outro erro é centrar o que se pretende ensinar somente por meio de (d) ações dos aprendizes, sem discriminar o que o aluno já sabe (nível de base), aspectos do ambiente necessários à aprendizagem (similares ao ambiente onde o aluno estará inserido como profissional) e resultados (ou produtos) a serem atingidos, o que também não garante que objetivos de ensino sejam desenvolvidos. Botomé (1987) salientou ainda que não basta ao aluno responder diferencialmente a situações preparadas pelo professor em ambiente escolar; é necessário que ele consiga se comportar onde é necessário que ele produza algum tipo de intervenção como profissional e faça mais do que replicar (e) atividades de ensino. Talvez isso ajude a compreender por que há situações em que alunos "Nota 10 " se tornam péssimos profissionais ou nem isso conseguem. Outro problema está em (f) utilizar de informações tradicionalmente apresentadas como itens de conteúdo modificadas para parecerem objetivos de ensino, como se produzir objetivos de ensino fosse apenas uma mudança de dialeto em uma língua ineficiente. É necessário a quem programa o ensino avaliar quais os componentes envolvidos no aprendizado do aluno e confrontar seu modo de trabalho com o conhecimento disponível, especialmente em Psicologia, para verificar melhores formas de definir objetivos de ensino e atividades condizentes com esses objetivos.

\section{A Função de Planos de Ensino para os Cursos de Ensino Superior}

Ao examinar um segmento de uma organização denominado recursos humanos, o qual pode constituir um subcampo de atuação profissional tanto da Psicologia quanto da Administração de Empresas, Kienen e Wolff (2002) ressaltaram que para administrar o comportamento humano é necessário reconhecer três princípios básicos da Análise Experimental do Comportamento: (a) o comportamento é um tipo de relação entre ambiente ou situação antecedente e consequente e as ações das pessoas, sendo modificado a cada variação de um de seus aspectos; (b) as ações, ou classes de respostas, são multideterminadas, sendo necessário identificar quais as variáveis envolvidas no processo; (c) 
as pessoas agem no mundo conforme um histórico de experiências pessoais (ontogênese), seu aparato biológico, herdado de seus progenitores (filogênese), e a partir de outras variações no ambiente (cultura). Para que esteja claro o que os alunos de um curso superior necessitam aprender, é necessário traçar objetivos de ensino claros, compostos pelos mesmos princípios da Análise Experimental do Comportamento: (a) a situação inicial em relação a que o organismo age, onde se incluem os aspectos relevantes no aprendiz e outros aspectos do ambiente; (b) a ação do organismo, descrita por meio de verbos; (c) a situação final, envolvendo o efeito da ação no aluno em relação ao ambiente (Botomé \& Souza, 1982). A descrição dos objetivos de ensino a serem aprendidos pelo aluno, assim como a forma e os subsídios de ensino utilizados pelo professor são essenciais ao plano de ensino.

Como resultado das relações entre a situação inicial (antecedente à ação, condição sob a qual o aluno se encontra), a ação do professor (o "ensinar" do professor, geralmente descrito como um conjunto de atividades) e a situação consequente a essa ação (aluno capaz de fazer algo, ensinado pelo professor), os objetivos de ensino podem ser desenvolvidos. O plano de ensino vem a ser um tipo de contrato entre o professor e o aluno em que há, fundamentalmente, a explicitação do que deverá ser garantido como aprendizagem para os alunos. Sem que estejam claros os objetivos de ensino, corre-se o risco de que seja feito um "contrato" desconhecido: professor e aluno concordam em assinar uma folha em branco onde "qualquer coisa" pode ser escrita, tornando menos provável que ocorram os processos de ensinar e de aprender.

Mintzberg (1993) concluiu que, mesmo que administradores de empresas declarem planejar os processos (de gerir comportamentos?) sob sua responsabilidade, a maior parte do tempo é dedicada a ações rotineiras e de curta duração. Atuações como essas são, muito provavelmente, produtos de cursos "alienantes" construídos a partir de "disciplinas" centradas na "transposição de conteúdos" que produzem professores e alunos alienados ao que seria o objeto principal de suas ações: o aprendizado no aluno. Nicolini (2003) utilizou como metáfora a visualização de uma organização de ensino tal qual uma antiga fábrica, onde o professor ficaria em sua sala produzindo componentes que deveriam compor um produto final (ações ou atividades) sem entender como cada peça se encaixa nas demais (situação inicial e final no aluno), para que serve o produto e como ele funciona. Uma formação voltada para o mercado de trabalho e a baixa compreensão sobre o que seria fenômeno administrativo, por sua vez, resultam em uma diminuta produção científica sobre formação em Administração de Empresas. Mas, então, por que não mudar a maneira de ensinar? Como resposta parcial a essa pergunta, poderia ser inferido que a forma como os professores nos cursos de Administração de Empresas constroem planos de ensino faz parte e é mantida por contingências constituídas pelo modo como os funcionários interagem uns com os outros. Essas contingências são adotadas e mantidas pelos benefícios obtidos pelo grupo que as mantem (Miguel \& Garbi, 2003). Provavelmente os educadores estejam mais sob controle do grupo de profissionais com quem mantêm relações de poder e não das necessidades da comunidade que está mais distante desse círculo de relações. Estar sob controle das necessidades da sociedade em que os alunos serão inseridos e não (sob controle) de colegas de ofício desligados das necessidades sociais provavelmente selecionaria nos professores comportamentos de ensinar que produziriam benefícios para um contingente muito mais amplo da sociedade (Holland, 1983) - função maior da Universidade, seja ela materializada em uma organização de ensino superior pública ou privada. Ao que parece, o ensino de administrar empresas, ao atender apenas a interesses dos professores, pode estar mais próximo de gerar ou manter esses problemas do que de fomentar soluções para as organizações de ensino, saúde, produção e para a sociedade em geral.

\section{O Professor como Agente do Ensino ao Planejar a Generalização do que foi Aprendido, Possibilitando ao Aluno a Atuação Profissional em Nível Superior} A adaptação é uma das propriedades do comportamento das pessoas e a probabilidade de ocorrência de respostas de uma determinada classe aumenta em razão das consequências produzidas no ambiente (chamadas consequências reforçadoras). Assim, em ambientes similares ao ambiente inicial, 
as respostas dessa classe também poderão ocorrer com maior probabilidade, o que pode ser chamado de generalização do aprendizado (Botomé, Medeiros \& Kubo, 2006; Keller, 1965/1970; Kubo \& Botomé, 2001a; Kubo \& Botomé, 2001b; Matos, 2001; Skinner, 1953/2000). Os alunos que aprendessem a partir de planos de ensino com objetivos claros, formulados por professores socialmente responsáveis, provavelmente teriam maiores chances de desempenhar ações mantidas por contingências favoráveis à manutenção de um repertório de comportamentos coerente com a sua formação. Alguns desses alunos se tornariam professores, permitindo e garantindo assim a sobrevivência do próprio grupo de produtores de conhecimento. Aprender a se comportar de modo coerente com o objetivo de ensino, mesmo com uma variação no ambiente, é o que pode se chamar de aprendizado eficaz; o repertório é ampliado com a generalização de comportamentos a partir de um comportamento aprendido, levando a novos componentes de uma classe ou mesmo gerando uma nova classe de comportamentos.

Aprender a construir conhecimento não é obstáculo aos professores dos alunos de Administração de Empresas. Produzir conhecimento é fundamental para ensinar comportamentos profissionais de produzir conhecimento que propicia melhorias nas próprias competências profissionais a serem ensinadas e desempenhadas pelos profissionais. Não há uma verdadeira relação de disputa entre Ciência e Trabalho, mas sim uma relação de complementaridade (Ribeiro, 1969). O conhecimento produzido sobre uma dimensão do fenômeno pode ser utilizado em um Campo de Atuação Profissional a curto prazo, assim como atividades realizadas em um Campo de Atuação Profissional podem gerar informações novas a serem reunidas e organizadas na ampliação do conjunto de conhecimentos de uma Área do Conhecimento. Talvez por desconhecer a função do ensino, alguns professores ainda apresentem planos de ensino baseados na metáfora continente-conteúdo - segundo a qual o conhecimento é algo que pode ser transposto de um corpo para outro, completando um espaço a ser preenchido no aluno (Nicolini, 2003). Para o professor, identificar objetivos educacionais torna mais fácil indicar quais comportamentos do pró- prio professor e do aluno são necessários para que o aluno aprenda. Discriminados os comportamentos a serem aprendidos pelo aluno, é possível planejar ambientes que propiciem a ocorrência de tais comportamentos (Kienen \& Wolff, 2002). Essas características precisam ser discriminadas e garantidas por um contrato, que é a própria função formal do plano de ensino. Portanto, as informações contidas em planos de ensino de disciplinas possibilitam aferir a qualidade e a pertinência do que está sendo objeto de ensino do professor em cursos de formação de nível superior.

\section{O Fenômeno Psicológico, o Fenômeno Administrativo e a Relação entre Psicologia e Administração de Empresas na \\ Graduação em Administração de Empresas} A Psicologia, definida como uma área do conhecimento científico, tem como objeto de estudo o comportamento dos organismos (Skinner, 1953/2000). Adjetivos adicionados à expressão psicologia indicam aspectos do fenômeno psicológico, recortes tênues e controvertidos, dado que a fragmentação da Psicologia não está baseada em critério único, tal como Duran (1983) examina. O critério que preside a classificação das subáreas da Psicologia é diferente para cada título, como experimental, desenvolvimento, inteligência, clínica, patologia e etc. Não se trata de um sistema de classificação utilizando um mesmo critério. Trata-se de uma nomeação um tanto arbitrária que produz segmentos que se superpõem (Duran, 1983), cuja utilidade é mais histórica do que funcional. As disciplinas com nomes diferentes, sem critério claro ao que se propõem a ensinar são evidências da baixa visibilidade sobre o fenômeno psicológico. Geralmente versam sobre algum tipo de fragmento do fenômeno psicológico nem sempre referente ao que um aluno de um curso de Administração de Empresas necessitaria aprender em sua capacitação em nível superior. A fragmentação sem um critério claro e único torna-se um aspecto que dificulta a compreensão de quais seriam precisamente as subáreas constituintes de uma área tal como a Psicologia ou a Administração de Empresas (Botomé, 2001; Paviani \& Botomé, 1993; Rohrbacher, 2009).

Qual a subárea da Psicologia mais necessária à capacitação de administradores de empre- 
sas? Provavelmente a que se refere a uma subárea do conhecimento que é campo de atuação comum a administradores e psicólogos, a Psicologia Organizacional, pois importa ao administrador de empresas (e ao psicólogo inserido em organizações) um fenômeno mais restrito que o comportamento dos organismos em geral: o comportamento humano em contexto organizacional. É necessário produzir aprendizagem de comportamentos profissionais no aluno de Administração de Empresas para que este se torne capaz de lidar com o fenômeno psicológico no contexto das organizações, com processos de gestão no local onde o aluno necessitará intervir como profissional administrador de empresas depois de formado.

Apresentar conhecimento sobre o fenômeno psicológico como processos básicos é importante para a compreensão do comportamento por qualquer profissional (Rebelatto \& Botomé, 1999) e necessita ser feito com minúcia e abrangência, sobretudo na formação de profissionais como os psicólogos, que lidam com comportamento em qualquer contexto de intervenção. No entanto, o aluno de um curso de administração de empresas deve aprender comportamentos profissionais que sejam produto do conhecimento sobre o fenômeno psicológico em grau de abrangência menor em relação à formação de psicólogos, dado que o fenômeno de estudo e de intervenção do administrador de empresas é gerir comportamento humano em organizações (Rohrbacher, 2009).

A Psicologia como área de conhecimento tem muito a contribuir na capacitação de profissionais que lidam com comportamento de pessoas nos mais diferentes contextos de atuação profissional (Botomé, 1977; Botomé \& Kubo, 2002; Rebelatto \& Botomé, 1999). Dado que grande parte dos processos organizacionais depende de comportamentos de pessoas, é necessário que o administrador de empresas aprenda a lidar com comportamento humano. Essa exigência pode ser verificada nas diretrizes que orientam os projetos de cursos de graduação em Administração de Empresas, como, por exemplo, na frase "reconhecer e definir problemas em contexto organizacional" (Brasil, 2005). Nessa frase, é possível identificar algumas "competências e habilidades" exigidas do administrador que envolvem ser capaz de lidar com processos compor- tamentais básicos no contexto das organizações. Caso se considere que "lidar com comportamento humano" envolve, da mesma forma, que o profissional seja capaz de modificar as relações que organismos estabelecem com aspectos do seu meio, a relevância da capacitação para lidar com técnicas e procedimentos fundamentados em conhecimento psicológico se torna mais evidente.

Compete aos professores universitários identificar, avaliar e utilizar conhecimento científico de modo que este seja subsídio para ensinar aos alunos a identificar, avaliar e utilizar informações úteis no conhecimento disponível (Botomé \& Kubo, 2002). $\mathrm{O}$ professor que não for ensinado a reconhecer $\mathrm{e}$ a lidar com o fenômeno psicológico tende a diminuir a importância desse conhecimento na formação dos alunos, tornando a Psicologia foco de apenas uma ou duas disciplinas do curso, por ser previsto nas diretrizes curriculares para cursos de Administração de Empresas.

\section{Método}

Foram utilizadas como fontes de informação as diretrizes curriculares e os planos de ensino das disciplinas que compõem os currículos de cursos de graduação em Administração de Empresas de quatro organizações de ensino de um estado do sul do Brasil. Foram selecionados os cursos mais antigos dentre as maiores universidades do estado. $\mathrm{O}$ Curso A era o mais antigo, reconhecido em 1970 junto ao Conselho Federal de Educação. Fazia parte de uma organização de ensino superior pública situada na capital com currículo semestral, oferecia 80 vagas no curso de Administração de Empresas por semestre, 40 em período vespertino e $40 \mathrm{em}$ período noturno, em um total de oito semestres. $\mathrm{O}$ Curso B era o segundo mais antigo do estado, reconhecido junto ao Conselho Federal de Educação em 1975. Fazia parte de uma organização de ensino superior pública de ensino situada na capital. Com currículo semestral, oferecia 100 vagas por semestre, 50 em período vespertino e 50 em período noturno em um total de nove semestres. Este era o único a apresentar disciplinas optativas, seis oferecidas pelo departamento e oito disciplinas fornecidas por outros cursos. O Curso C fazia parte de uma fundação de direito privado, reconhecido em 1978, com currículo semestral em um total de oito 
semestres. O Curso $\mathrm{C}$ não divulgava o número de vagas oferecidas por semestre ou ano. O Curso D, reconhecido em 1999, fazia parte de uma entidade pública de direito privado situada ao sul do estado. O curso era semestral, recebendo 50 alunos por semestre em um total de oito semestres. Os planos de ensino de três cursos estavam disponíveis na internet, as informações do outro curso foram conseguidas por meio de um professor que lecionava na organização de ensino. Foram utilizadas todas as disciplinas de três cursos e somente as obrigatórias do curso que apresentava disciplinas obrigatórias e optativas. Foram observados os nomes de disciplinas contendo expressões que indicavam aspectos do conhecimento psicológico e nomes de disciplinas sem expressões que indicavam aspectos do conhecimento psicológico, ou seja, o fenômeno psicológico relacionado ou não ao fenômeno administrativo. Não foram considerados para este trabalho os processos básicos do comportamento indicados por verbos sem complementos (e.g., ensinar, ler e escrever). Foi verificada a distribuição dessas disciplinas durante os semestres utilizados para formar o profissional graduado em Administração de Empresas. Além dos dados de identificação (nome da disciplina, período ou fase dos alunos para o qual a disciplina era oferecida), foram observados em cada disciplina a ementa, o objetivo geral e os objetivos específicos (se houvesse).

Após transcrever o número do plano de ensino, identificado com a letra correspondente à organização de ensino superior, o semestre e o nome de cada uma das disciplinas, foram transcritos em tabela os textos integrais que compunham ementa, objetivo geral e objetivos específicos. A partir dessas informações, ocorreram dois procedimentos distintos, um de análise da ocorrência de expressões que indicassem aspectos do conhecimento psicológico nos nomes das disciplinas e outro de análise da ocorrência de expressões que indicassem aspectos do conhecimento psicológico nas partes que compunham os planos de ensino. As sentenças que continham expressões que indicavam aspectos do conhecimento psicológico foram destacadas em cada componente dos planos de ensino. Foram descartados os planos que não continham expressões que indicavam aspectos do conhecimento psicológico, mesmo que ocorressem aspectos do conhecimento psicológico nos nomes dessas disciplinas. Posteriormente, os planos restantes, que continham expressões que indicavam aspectos do conhecimento psicológico, foram subdivididos em partes: ementa, objetivo geral e objetivos específicos. As sentenças que continham mais de um núcleo em ementa, objetivos gerais e $o b$ jetivos específicos foram decompostas de modo que cada para expressão derivada fosse ordenada como uma unidade de análise. $\mathrm{O}$ procedimento seguinte foi quantificar as novas unidades. Pôde-se então verificar a quantidade de expressões que continham aspectos do conhecimento psicológico e a sua distribuição nos planos de ensino das disciplinas dos quatro cursos de graduação em Administração de Empresas.

Um exame que ocorreu em paralelo à verificação da quantidade de expressões foi a identificação de expressões que indicavam aspectos do conhecimento psicológico nos nomes das disciplinas de cada um dos cursos de graduação em Administração de Empresas. As disciplinas que apresentavam expressões que indicavam aspectos do conhecimento psicológico em seus nomes foram destacadas. Na mesma tabela, também foi assinalado em que partes do plano de ensino examinadas havia expressões que indicassem aspectos do conhecimento psicológico. A análise dos dados, conforme os critérios de discriminação de categorias de aspectos do conhecimento psicológico localizados nos planos de ensino, permitiu a comparação da ocorrência de expressões que indicavam aspectos do conhecimento psicológico entre as partes que compunham os planos de ensino das disciplinas dos cursos de graduação em administração de empresas em relação às disciplinas que apresentavam expressões que indicavam aspectos do conhecimento psicológico em seus nomes. As expressões que apresentavam algum aspecto do conhecimento psicológico nas ementas, objetivos gerais e objetivos específicos das disciplinas que compunham os quatro cursos de graduação em Administração de Empresas foram agrupadas em categorias: fenômenos psicológicos, fenômenos comuns à Psicologia e a outras áreas do conhecimento, escolas psicológicas e técnicas e procedimentos, por curso. Os fenômenos psicológicos inseridos nos planos de ensino foram separados nessas categorias de acordo com seus complementos. Com isso, alguns termos iguais foram distribuídos em categorias diferentes. 
Dada a dimensão da categoria fenômenos comuns à Psicologia e a outras áreas do conhecimento, esta foi desdobrada para evidenciar diferentes tipos de fenômenos em dois grandes grupos: as expressões que indicavam fenômenos administrativos e as que não indicavam.

\section{Resultados}

Na Figura 1, são apresentados os percentuais de ocorrência dos aspectos do conhecimento psicológico verificados nas expressões localizadas nos planos de ensino dos currículos dos quatro cursos de graduação em Administração de Empresas.

\section{Figura 1}

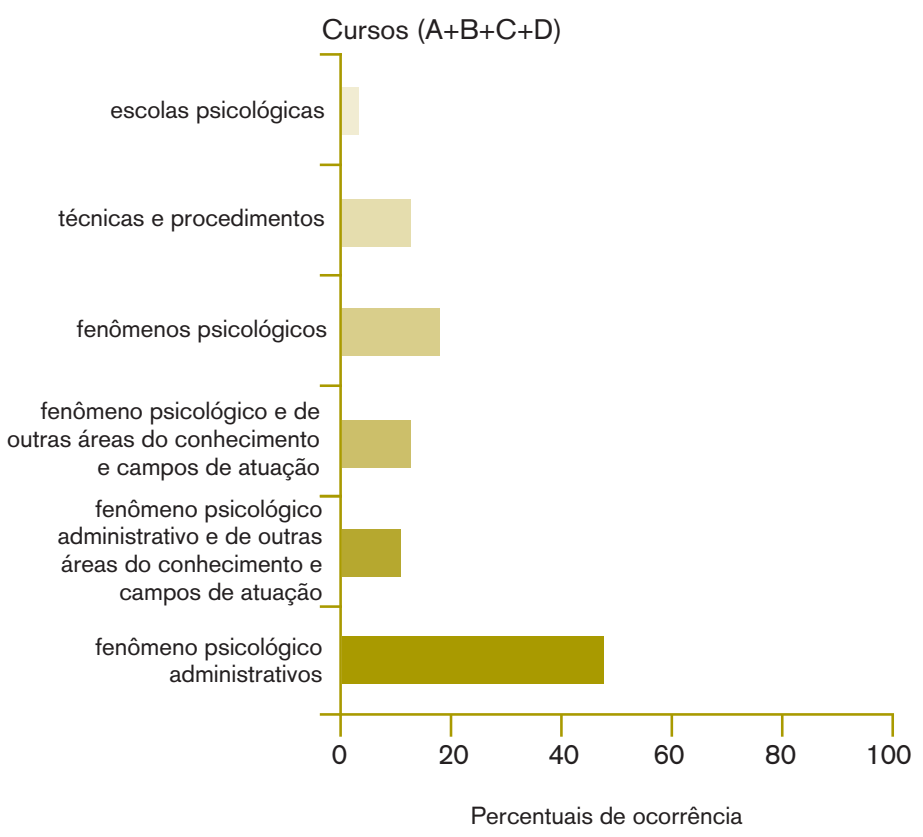

Figura 1. Distribuição dos percentuais de ocorrência de aspectos do conhecimento psicológico identificados pelas expressões presentes nos planos de ensino dos quatro cursos de graduação em Administração de Empresas organizados por categorias.

Quatro são as categorias: (a) fenômeno psicológico e administrativo apresenta $45.91 \%$ das ocorrências de aspectos do conhecimento psicológico, enquanto a categoria (b) fenômeno psicológico, administrativo e de outras áreas do conhecimento e campos de atuação apresenta $11.73 \%$, (c) fenômeno psicológico e de outras áreas do conhecimento e campos de atuação corresponde a $10.96 \%$, (d) fenômenos psicológico apresenta $17.95 \%$, (e) técnicas e procedimentos tem índice de $11.81 \%$ e (f) escolas psicológicas, $1.65 \%$ do total das expressões selecionadas.

Na Figura 2 estão representados os percentuais de ocorrência de aspectos do conhecimento psicológico em expressões selecionadas nos planos de ensino. Os aspectos do conhecimento psicológico contidos nas ementas, objetivos gerais e objetivos específicos estão distribuídos em quatro categorias: fenômenos psicológicos, fenômenos comuns à Psicologia e a outras áreas, técnicas e procedimentos e escolas psicológicas.

As ementas do Curso A apresentam em fenômenos comuns à Psicologia e a outras áreas $31.34 \%$ do total de expressões que contêm aspectos do conhecimento psicológico, técnicas e procedimentos apresenta $5.97 \%$, enquanto fenômenos psicológicos e escolas psicológicas apresenta $1.49 \%$ do total de expressões. Nos objetivos gerais, $12.67 \%$ das expressões estão em fenômenos comuns à Psicologia e a outras áreas, $6.72 \%$ em técnicas e procedimentos, $3.73 \%$ em fenômenos psicológicos e 1,49\% em escolas psicológicas. Objetivos específicos têm $25.37 \%$ das expressões em fenômenos comuns à Psicologia e a outras áreas, $3.73 \%$ em fenômenos psicológicos e $2.99 \%$ em técnicas e procedimentos e escolas psicológicas.

O Curso B apresenta em suas ementas $37.18 \%$ das expressões que contêm aspectos do conhecimento psicológico como fenômenos comuns à Psicologia e a outras áreas, 8,33\% como técnicas e procedimentos, $3.85 \%$ como fenômenos psicológicos e nenhuma expressão como escolas psicológicas. Para as expressões localizadas nos objetivos gerais, $15.54 \%$ referentes a fenômenos comuns à Psicologia e a outras áreas, $5.13 \%$ das expressões em técnicas e procedimentos, $4.49 \%$ em fenômenos psicológicos, sem expressões de escolas psicológicas. Quanto aos objetivos específicos, $23.72 \%$ das expressões foram categorizadas como fenômenos comuns à Psicologia e a outras áreas, técnicas e procedimentos apresentam $4.49 \%$ das expressões, $1.28 \%$ são referentes a fenômenos psicológicos e não há expressões que indiquem aspectos do conhecimento psicológico em escolas psicológicas.

As expressões encontradas no Curso C são distribuídas nas ementas com $22.26 \%$ a fenômenos comuns à Psicologia e a outras áreas, $8.48 \%$ a fenômenos psicológicos, $4.24 \%$ a técnicas e procedimentos e $1.77 \%$ a escolas psicológicas. Os aspectos do conhecimento psicológico nos objetivos gerais 


\section{Figura 2}
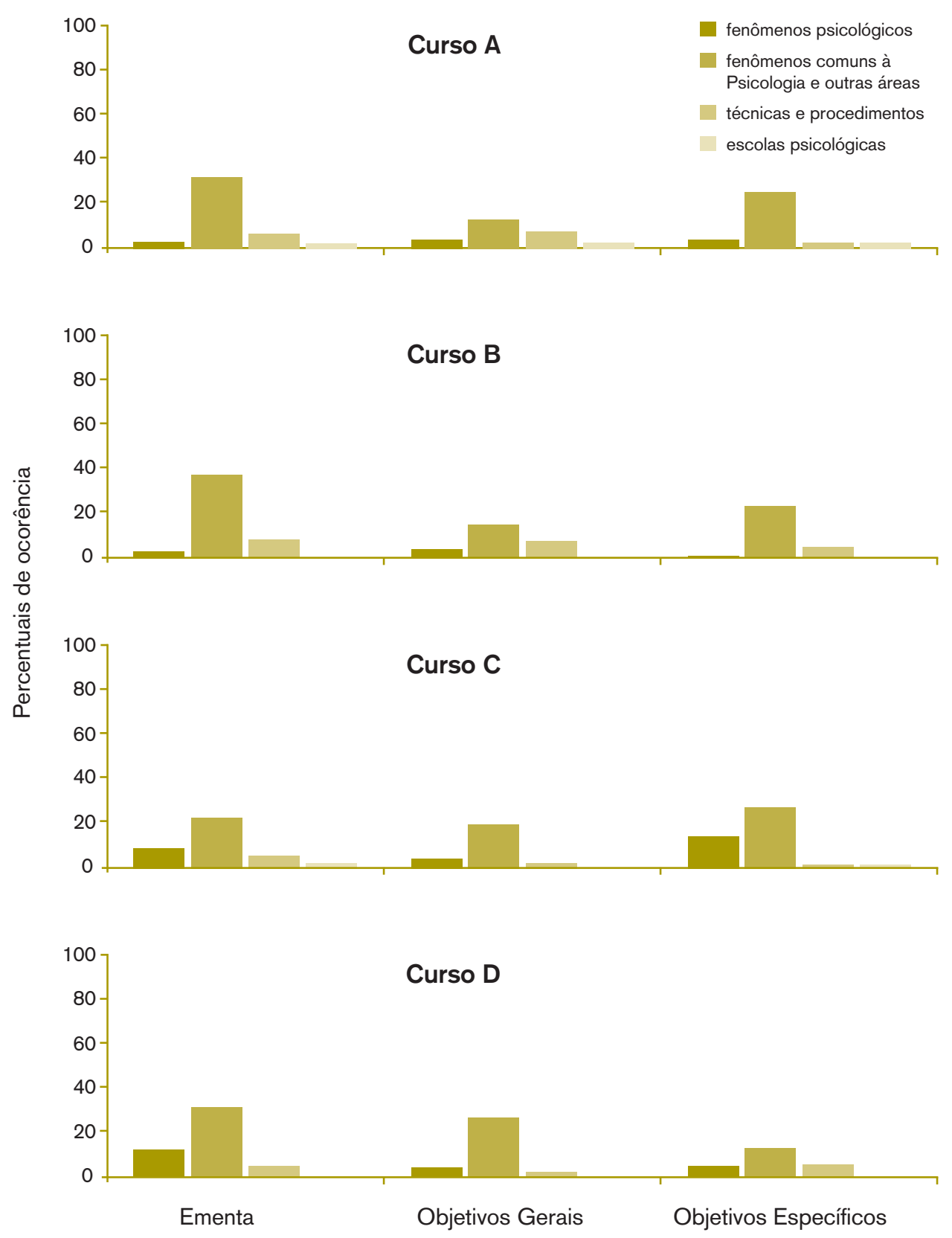

Figura 2. Distribuição de percentuais de ocorrência de aspectos do conhecimento psicológico identificadas pelas expressões nos componentes dos planos de ensino dos cursos de graduação em Administração de Empresas A, B, C e D, organizados por categorias elaboradas de acordo com os referentes (fenômenos psicológicos, fenômenos comuns à Psicologia e outras áreas do conhecimento, técnicas e procedimentos e escolas psicológicas).

do Curso C distribuem-se com $18.73 \%$ das expressões na categoria fenômenos comuns à Psicologia e a outras áreas, $4.24 \%$ a fenômenos psicológicos, $1.41 \%$ das expressões a técnicas e procedimentos e nenhuma ocorrência pode ser verificada para escolas psicológicas. Nos objetivos específicos, estão representadas $25.09 \%$ das expressões em fenômenos comuns à Psicologia e a outras áreas, $13.07 \%$ em fenômenos psicológicos e $0.35 \%$ em técnicas e procedimentos e escolas psicológicas.

As ementas do Curso D representam fenômenos comuns à Psicologia e a outras áreas com 29.93\% do total de expressões que contêm aspectos do conhecimento psicológico, fenômenos psicológicos 
representam $12.04 \%$, técnicas e procedimentos representam $4.38 \%$ e escolas psicológicas nada representam no total de expressões. Nos objetivos gerais, $25.91 \%$ das expressões representam fenômenos comuns à Psicologia e a outras áreas, 3.28\% fenômenos psicológicos, 2.19\% técnicas e procedimentos. A categoria escolas psicológicas não apresentou qualquer expressão. Objetivos específicos tiveram 12.77\% das expressões a representar fenômenos comuns à Psicologia e a outras áreas, $5.84 \%$ a técnicas e procedimentos e $3.65 \%$ das expressões correspondem a fenômenos psicológicos, não ocorrendo expressões referentes a escolas psicológicas.

\section{Discussão}

As distribuições das quantidades de expressões que indicam conhecimento psicológico representadas na Figura 1 possibilitam avaliar o grau de importância do conhecimento psicológico para a capacitação do administrador de empresas em nível superior por meio da quantidade de expressões que se referem às relações entre fenômeno psicológico, fenômeno administrativo e fenômenos objeto de outras áreas ou de outros campos de atuação. Expressões que se referem ao fenômeno psicológico são identificadas em $46 \%$ do total das disciplinas dos planos de ensino em relação estrita com o fenômeno administrativo e em $22.6 \%$ das expressões que indicam relação do fenômeno psicológico com fenômenos administrativo e de outras áreas de conhecimento. Além disso, expressões que se referem ao fenômeno psicológico e a aspectos específicos desse conhecimento, como escolas psicológicas e técnicas e procedimentos, perfazem $31.4 \%$ do total de expressões encontradas nos planos de ensino. Essa distribuição de aspectos do conhecimento psicológico indica o grau de importância do conhecimento sobre o fenômeno de estudo e intervenção da Psicologia para a capacitação de administradores de empresas, seja como conhecimento básico sobre o comportamento humano ou, principalmente, na relação com o fenômeno administrativo: gerir comportamento humano em organizações (Rohrbacher, 2009).

Administração de Empresas é um dos cursos de graduação no qual ensinar futuros profissionais a lidar com processos que envolvam o comportamento de pessoas é fundamental. No entanto, há neces- sidade de estabelecer os limites dessa capacitação para distinguir a intervenção de um administrador daquela que caberia ao psicólogo. Ainda que $46 \%$ do total das expressões identificadas nos planos de ensino se refiram à relação entre conhecimento sobre fenômeno psicológico e fenômeno administrativo, $31.4 \%$ do total das expressões se referem estritamente ao conhecimento sobre fenômeno psicológico, a técnicas e procedimentos derivados diretamente do conhecimento psicológico e a escolas psicológicas. Essa quantidade de expressões que se referem à área e ao campo específico da Psicologia indica a necessidade de avaliar nos currículos dos cursos de Administração de Empresas se e quanto o conhecimento sobre fenômeno psicológico como conhecimento sobre processos básicos assegura o desenvolvimento de comportamentos profissionais próprios que possibilitam identificar a atuação do administrador de empresas pela delimitação clara e precisa de seu objeto de intervenção.

Outro aspecto que se destaca está relacionado à quantidade de expressões que se referem ao conhecimento sobre fenômenos objeto de estudo ou de intervenção das distintas áreas e campos indicados nos planos de ensino das disciplinas dos cursos de administração de empresas examinados. A única categoria que não se refere a apenas "transpor informações" é técnicas e procedimentos que soma apenas $11.8 \%$ do total de expressões encontradas, os $88.2 \%$ restantes correspondem ao "conhecimento" ou "conteúdo". Os cursos de graduação em Administração de Empresas apresentam informações sobre comportamento na forma de temas ou assuntos. Em consonância com a relevância do papel do conhecimento para a formação de qualquer profissional de nível superior, conforme Botomé e Kubo (2002) salientam, a transformação de conhecimento psicológico em técnicas e procedimentos em proporção mais equilibrada em relação à quantidade de conhecimento sobre conceitos e princípios descritos e estudados em Psicologia com os quais administradores de empresas se beneficiariam em sua atuação evidenciaria contribuição da Psicologia para a qualificação desses futuros profissionais.

A proporção de expressões encontradas nos planos de ensino examinados indica quantidade relativamente pequena das expressões que se referem 
a técnicas e procedimentos (11.8\%) no total de expressões que se referem a conhecimento na forma de assunto, tema, conceitos e princípios (88.2\%). Ainda que não possa ser afirmado que todas as expressões encontradas se refiram estritamente a conhecimento, é possível conjecturar se a contribuição do conhecimento psicológico na forma de técnicas e procedimentos poderia ser maior, dada a grande quantidade de conhecimento produzido e disponível na literatura sobre comportamento humano, principalmente sobre o comportamento das pessoas nas organizações (Gomes, 2005; Kienen, 2008; Kubo \& Botomé, 2001b; Luiz, 2008; Malott \& Garcia, 1987; Teixeira, 2006; Tosi, 2005; Viecili, 2005), e a equivalente transformação de conhecimento em tecnologias para intervenção que podem se constituir em "ferramentas" para o trabalho não só do administrador de empresas, como de qualquer profissional.

A partir dos planos de ensino examinados, foi observada baixa proporção relativa de expressões que indicam técnicas e procedimentos derivados ou fundamentados em conhecimento psicológico ante a quantidade de expressões que indicam conceitos, assuntos, temas, princípios. Os professores desconhecem a contribuição da Psicologia sob a forma de técnicas e procedimentos? O conhecimento psicológico sob a forma de técnicas e procedimentos não está suficientemente divulgado ou está pouco acessível? O conhecimento psicológico é considerado pouco relevante para a graduação de administradores de empresas? O uso de expressões pouco claras encobre o conhecimento psicológico nos planos de ensino? A investigação dessas questões pode preencher lacunas importantes na formação de administradores em nível superior.

O Plano de Ensino da disciplina é de responsabilidade do professor, pois é ele quem estabelece este contrato de ensino com o aluno. $\mathrm{O}$ que os professores fazem, como planejam o aprendizado de seus alunos e os registram em seus planos de ensino podem indicar o que esses professores aprenderam na sua capacitação formal, especialmente quanto ao conhecimento sobre comportamento humano. Contudo, os currículos de cursos similares entre as graduações podem indicar que os planos de ensino não são construídos pelos professores que desempenham seu trabalho nas universidades, uma con- fusão entre currículo de curso e plano de ensino. Os planos de ensino fixos, não passíveis de mudança pelos professores, encobririam o que de fato se pretende ensinar aos alunos.

A apresentação de expressões como "dinâmica da liderança", "diagnosticar processos organizacionais" e "aprendizagem organizacional" nos planos de ensino examinados constituem alguns exemplos de como o conhecimento sobre o fenômeno psicológico pode ficar encoberto pelo uso de expressões pouco claras, que não indicam exatamente a quais fenômenos tais expressões se referem. O uso de expressões como as exemplificadas pode favorecer a identidade de uma determinada área, mas dificulta a avaliação da contribuição de diferentes áreas sobre os processos e fenômenos envolvidos e referidos por tais expressões. Isso se torna especialmente relevante ao considerar que avanços do conhecimento e avanços tecnológicos são mais prováveis quando ocorre a integração de conhecimento de distintas áreas do saber.

Conforme verificado na Figura 2, as expressões que indicam fenômenos psicológicos aparecem mais nos cursos de Administração de Empresas $\mathrm{C}$ e $\mathrm{D}$, e essas expressões que indicam aspectos do conhecimento psicológico ocorrem distribuídas em maior quantidade em ementas $(8.5 \%$ e $12 \%$, respectivamente) e objetivos gerais $(4.5 \%$ e $3.3 \%$, respectivamente). Os cursos $\mathrm{C}$ e $\mathrm{D}$ são cursos mais recentes, em relação aos cursos A e B, reconhecidos ao final das décadas de 1970 e de 1990, respectivamente. Os cursos A e B não atualizam o conhecimento que é insumo do aprendizado de seus alunos? É provável que os cursos $\mathrm{C}$ e $\mathrm{D}$ já considerem em suas proposições o conhecimento psicológico não só do ponto de vista da quantidade desse conhecimento, como também aquele mais recente que envolve, por exemplo, conhecimento sobre programação de ensino como interações comportamentais entre ensino do professor e aprendizagem no aluno. Considerar o avanço do conhecimento psicológico sobre os processos de ensinar e aprender, principalmente depois da década de 1980 na qual o desenvolvimento de programas de ensino se difundiu como procedimento para planejar ensino e também como conjunto de competências para formar um professor (Botomé, 1981; Kubo \& Botomé, 2001b; Matos, 2001; Nale, 
1998), permite identificar mais facilmente a contribuição da Psicologia para os processos de ensino e de aprendizagem, úteis para os profissionais de quaisquer áreas ou campos de atuação.

Dos quatro cursos que fizeram parte da amostra examinada neste estudo, os cursos $\mathrm{A}$ e $\mathrm{C}$ foram os únicos a apresentar expressões relativas a escolas psicológicas nos planos de ensino de suas disciplinas. O Curso D não apresenta tais expressões, assim como o Curso B, embora este último fosse o único a apresentar disciplinas optativas, não examinadas, que poderiam conter expressões que indicassem conhecimento sobre escolas psicológicas. Nos planos de ensino dos cursos B e D podem ser observados de modo muito evidente indicadores da relação entre conhecimento administrativo e psicológico, assim como muitas relações entre estes e conhecimentos de outras áreas (Figura 2). É possível conjecturar que os professores propositores dos planos de ensino dos cursos B e D provavelmente têm clara a relevância das contribuições de outras áreas do conhecimento para a formação de seus alunos. Nesses cursos, há grande quantidade expressões que indicam relações entre conhecimento administrativo e psicológico, apresentadas em ementas, objetivos gerais e objetivos específicos representados na Figura 2, com índices superiores a 1/3 das expressões contidas nas ementas. Nos planos de ensino dos cursos $\mathrm{B}$ e $\mathrm{D}$, há incidência menor de expressões que indicam somente "conhecimento psicológico", como pode ser verificado nas ementas apresentadas na Figura 2: 1.49\% do Curso A, 3.85\% do Curso B, $8.48 \%$ do Curso C e $12.04 \%$ das expressões que indicam aspectos do conhecimento psicológico do Curso $\mathrm{D}$, ou de outra área isoladamente do conhecimento administrativo, como o conjunto categorizado pelo nome escolas psicológicas, em comparação com os planos dos cursos A e C.

Os cursos mais antigos (A e B) são referência no estado e podem ter servido como modelo para os mais novos (C e D). O Curso A, mais antigo dentre eles (reconhecido em 1970), é o que apresenta maior percentagem de expressões que indicam apresentação de informações sobre escolas psicológicas ( $1.44 \%$ em ementas e objetivos gerais; $2.99 \%$ em objetivos específicos). Algumas expressões que exemplificam informações sobre escolas psicológicas são: "escolas psicológicas aplicadas às organizações", "mentalidade das escolas psicológicas" e "pensamento humano nas escolas psicológicas". O Curso C é o que mais se aproxima de A nesse aspecto, enquanto B não apresenta expressões que indiquem esse tipo de conhecimento nas disciplinas obrigatórias (as disciplinas optativas não foram analisadas e deixam dúvidas quanto ao conhecimento sobre escolas psicológicas ser apresentado ou não em seus planos de ensino). $\mathrm{O}$ único que com certeza não apresenta esse tipo de conhecimento nos planos de ensino é o Curso $\mathrm{D}$, o mais recente (reconhecido em 1999). Informações sobre escolas psicológicas não contribuem para a formação de Administradores de Empresas; fazem parte da formação histórica de psicólogos em suas graduações. Os alunos teriam muito mais proveito em seu futuro profissional com uma concepção científica da Psicologia, como estudo de processos comportamentais constituídos pelas relações entre o que as pessoas fazem e o ambiente existente e modificado por essas ações (Botomé, 2001; Keller, 1965/1970; Kubo \& Botomé, 2003; Matos, 2001; Sidman, 1989/1995; Skinner, 1953/2000; Skinner, 1989/1995). Planos de ensino que contenham informações sobre escolas psicológicas, mesmo em pequena quantidade, podem indicar que parte dos professores que planejam o ensino em disciplinas dos cursos de graduação equivocadamente priorizam conhecimentos que serão de pouca valia à formação de administradores de empresas. Isso porque, muito provavelmente, esses professores estão despreparados para acompanhar o desenvolvimento das áreas ou de campos de atuação que culminam em novas exigências para capacitar profissionais de nível superior. Por exemplo, esses professores podem estar despreparados ou desatualizados em relação aos avanços no conhecimento psicológico e sobre a sua importância para a capacitação de qualquer profissional (Kubo \& Botomé, 2003; Rebelatto \& Botomé, 1999), cuja contribuição é evidenciada pela relação entre esse conhecimento e outros. Ou pode ocorrer algo ainda mais grave, suposto a partir das similaridades entre o Curso A e o Curso C, que os profissionais que deveriam planejar o ensino e descrever esse planejamento nos planos de ensino se limitam a transcrever os 
planos de ensino de cursos mais antigos sem avaliar a qualidade dos planos de ensino apresentados nesses cursos.

As ementas são constituídas por conjuntos de sentenças referentes a conteúdo e assuntos, como "desenvolvimento de pessoal", "relações com empregados" e "recursos humanos", os quais deveriam ser garantidos mais especificamente nos objetivos gerais ou nos objetivos específicos. Uma vez apresentados os fenômenos comuns na ementa como declarações de conteúdos, segundo o conceito de objetivos de ensino (Botomé, 1981) seria esperado que eles aumentassem em quantidade e precisão, tanto para objetivos gerais como para objetivos específicos. Contudo, isso não ocorre em três dos quatro cursos examinados, o que pode indicar que nesses cursos de Administração de Empresas as ementas são declarações vagas sobre o que se espera que ocorra a partir do curso, com poucas relações com o que se indica ensinar por meio dos objetivos gerais e dos objetivos específicos.

Embora as expressões que indicam aspectos do conhecimento psicológico estejam separadas por partes dos planos nos quais essas expressões foram identificadas, conforme ilustrado na Figura 2, elas não indicam necessariamente correspondência ponto a ponto em uma única disciplina. Uma disciplina poderia apresentar uma expressão que se refere ao fenômeno psicológico na ementa, outra em objetivo geral e ainda uma terceira na parte dos objetivos específicos. A quantidade de expressões distribuídas nas diferentes partes que compõem um plano de ensino não indica necessariamente coerência entre eles. Quem constrói planos de ensino (um professor em outra função) apresenta intenções vagas nas ementas, as quais podem não ser garantidas sob a forma de objetivos nos objetivos gerais e nos objetivos específicos descritos nos planos de ensino. Essa possibilidade indica que a presença de conhecimento psicológico nas diferentes partes dos planos de ensino de uma disciplina não garante a aprendizagem de comportamentos profissionais relevantes para o aluno de Administração de Empresas.

Em síntese, pôde ser verificado que a distribuição de aspectos do conhecimento psicológico nos planos de ensino dos cursos de graduação em Administração de Empresas indica o alto grau de importância do conhecimento sobre o fenômeno de estudo e intervenção da Psicologia para a capacitação de administradores de empresas, seja como conhecimento básico sobre o comportamento humano ou, principalmente, na relação com o fenômeno administrativo: gerir comportamento humano nas organizações. O conhecimento sobre o fenômeno psicológico poderia ser melhor aproveitado se houvesse maior equilíbrio entre a apresentação de conceitos e princípios descritos e estudados em Psicologia com técnicas e procedimentos produzidos a partir desse conhecimento. Esse equilíbrio poderia evitar que o uso de procedimentos e técnicas, desvinculado do aprendizado dos princípios de sua gênese, continue a contribuir para que os futuros profissionais avaliem erroneamente a necessidade do conhecimento de outras áreas do conhecimento e campos de atuação profissional. Os professores são os responsáveis pela construção dos planos de ensino de suas disciplinas e o que aprenderam na própria formação interfere no modo como irão ensinar e o que pretendem ensinar aos alunos. A repetição de alguns jargões próprios dos planos de ensino examinados favorece a identidade de uma determinada área, apropriando conhecimento de um campo de atuação à Administração de Empresas. Contudo, essas apropriações dificultam a avaliação da contribuição de diferentes áreas sobre os processos e fenômenos envolvidos e referidos por tais expressões. Isso se torna especialmente relevante ao considerar que avanços do conhecimento e avanços tecnológicos são mais prováveis quando ocorre a integração de conhecimento de distintas áreas do saber. $\mathrm{O}$ conhecimento sobre os processos de ensinar e aprender, que possibilitou avanços na construção de programas de ensino (Botomé, 1981; Kubo \& Botomé, 2001b; Matos, 2001; Nale, 1998), permite identificar mais facilmente a contribuição da Psicologia para os processos de ensino e aprendizagem, úteis para os profissionais de quaisquer áreas do conhecimento ou campos de atuação profissional. O uso de conhecimento desatualizado por parte dos professores aumenta a probabilidade de produzir profissionais aquém do seu tempo, bem como de mimetizar ou repetir esse conhecimento de outros planos de ensino (dos cursos mais antigos), o que vem a produzir danos ainda maiores à formação dos alunos. 


\section{Referências}

Botomé, S. P. (1977). Administração de comportamento humano em instituição de saúde: Uma experiência para Serviço Público (Dissertação de mestrado). Universidade de São Paulo, São Paulo, SP.

Botomé, S. P. (1981). Objetivos comportamentais no ensino: A contribuição da Análise Experimental do Comportamento (Tese de doutorado). Universidade de São Paulo, São Paulo, SP.

Botomé, S. P. (1987). Educação, conhecimento, comportamento humano e necessidades sociais (pp. 1-15). Texto correspondente ao primeiro capítulo do livro Como decidir o que ensinar: Objetivos de ensino, necessidades sociais e tecnologia educacional, não publicado.

Botomé, S. P. (2001). Sobre a noção de comportamento. Em: Feltes, H. P. de M. \& Zilles (orgs). Filosofia - Diálogos de horizontes. Porto Alegre: Editora da Pontifícia Universidade Católica de Porto Alegre, v. 1, p. 685-708.

Botomé, S.P. \& Kubo, O.M. (2002). Responsabilidade social dos programas de pós-graduação e formação de novos cientistas e professores de nível superior. Interação em Psicologia, 6, 81-110.

Botomé, S. P., Medeiros, J. G. \& Kubo (2006). Debate em aula expositiva na "disciplina" de aprendizagem, processos organizacionais e trabalho: Programa de Pós-graduação em Psicologia, Área 1, linha 2. Universidade Federal de Santa Catarina.

Botomé, S. P., \& Souza, D. G. de (1982). Linguagem: Uma classe de comportamentos com múltiplas funções. Texto não publicado, escrito para ser utilizado na disciplina Psicologia Geral para o Curso de Enfermagem da Universidade Federal de São Carlos.

Brasil (2005), Ministério da Educação (MEC), Conselho Nacional de Educação Superior. Resolução No 4 de 13 de junho de 2005 que institui as Diretrizes Curriculares Nacionais do Curso de Graduação em Administração, bacharelado, e dá outras providências.

Duran, A. P. (1983). Psicologia social: Entre a microscopia e a macroscopia do social. Trabalho apresentado no simpósio "Questões Atuais da Psicologia Social", durante a 35ª Reunião Anual da Sociedade Brasileira de Psicologia. Belém, PA.
Gomes, J. F. (2005). Dimensões críticas dos comportamentos que caracterizam a tarefa profissional de triar objetos de um agente de entrega de correspondência (Dissertação de mestrado). Programa de Pós-Graduação em Psicologia. Universidade Federal de Santa Catarina, Florianópolis, SC.

Holland, J. G. (1983) Comportamentalismo: Uma parte do problema ou da solução? Psicologia, 9, 59-75.

Keller, F. S. (1970). A definição da psicologia (R. Azzi, Trad.). São Paulo: Herder. (Trabalho original publicado em 1965).

Kienen, N. (2008) Classes de comportamentos profissionais do psicólogo para intervir, por meio de ensino, sobre fenômenos e processos psicológicos, derivadas a partir das diretrizes curriculares, da formação desse profissional e de um procedimento de decomposição de comportamentos (Tese de doutorado). Universidade Federal de Santa Catarina, Florianópolis, SC.

Kienen, N. \& Wolff, S. (2002). Administrar comportamento humano em contextos organizacionais. Psicologia: Organizações e Trabalho, 2, 11-37.

Kubo, O. M. \& Botomé, S. P. (2001a). Formação e atuação do psicólogo para o trabalho em saúde em organizações de atendimento à saúde. Interação em Psicologia, 5, 93-122.

Kubo, O. M. \& Botomé, S. P. (2001b). Ensinoaprendizagem: Uma interação entre dois processos comportamentais. Interação em Psicologia, 5, 133-171.

Kubo, O. M. \& Botomé, S. P. (2003). A transformação do conhecimento em comportamentos profissionais na formação do psicólogo: As possibilidades nas diretrizes curriculares. Em M. Z. S. Brandão et al. (Orgs.), Sobre comportamento e cognição: Vol. 11. A história e o avanços, a seleção por conseqüências em ação (pp. 483-496). Santo André: Esetec.

Luiz, E. C. (2008). Classes de comportamentos componentes da classe "projetar a vida profissional" organizadas em um sistema comportamental. (Dissertação de mestrado). Programa de PósGraduação em Psicologia. Universidade Federal de Santa Catarina, Florianópolis, SC. 
Malott, R. W., \& Garcia, M. E. (1987). A goal direct model for the design human performance systems. Journal of Organizational Behavior Manegement. 9, 1, 125-159.

Matos, M. A. (2001). Análise de contingências no aprender e no ensinar. Em: E. M. S de Alencar (Org.), Novas contribuições da Psicologia nos processos de ensino e aprendizagem (4a ed., pp.141-165). São Paulo: Cortez.

Miguel, C. F. \& Garbi, G. (2003). Assertividade no trabalho: Descrevendo e corrigindo o desempenho dos outros. Em: F. C. Conte \& M. Z. Brandão (Orgs.), Falo ou não falo? Expressando sentimentos e comunicando idéias (pp. 129-140). Arapongas: Mecenas.

Mintzberg, H. (1993). El trabajo de la administracion: Fantasias y realidades. Em H. Mintzberg \& J. B. Quinn (Orgs.), El processo estratégico: Conceptos, contextos y casos (pp. 25-37). México: Prentice Hall Hispanoamericana.

Nale, N. (1998). Programação de Ensino no Brasil: O papel de Carolina Bori. Revista de Psicologia da USP,9(1), 275-301.

Nicolini, A. (2003). Qual será o futuro das fábricas de administradores? RAE-Revista de Administração de Empresas, 43(2), 44-54.

Paviani, J. \& Botomé, S. P. (1993). Interdisciplinariedade: Disfunções conceituais e enganos acadêmicos. Caxias do Sul: EDUCS.

Rebelatto, J. R. \& Botomé, S. P. (1999). Fisioterapia no Brasil: Fundamentos para uma ação preventiva e perspectivas profissionais. São Paulo: Manole.

Ribeiro, D. (1969). A universidade necessária. Rio de Janeiro: Paz e Terra.

Rohrbacher, C. L. (2009). Características do conhecimento produzido em psicologia nos planos de ensino de cursos de graduação em administração de empresas (Dissertação de mestrado). Programa de Pós-Graduação em Psicologia. Universidade Federal de Santa Catarina, Florianópolis, SC.

Sidman, M. (1995). Coerção e suas implicações (M. A. Andery \& T. M. Sério, T. M. Trads). Campinas: Editorial Psy (Trabalho original publicado em 1989).
Skinner, B. F. (2000). Ciência e comportamento humano (J. C. Todorov \& R. Azzi, Trads.). São Paulo: Martins Fontes. (Trabalho original publicado em 1953)

Skinner, B. F. (1995). O que terá acontecido com a psicologia como ciência do comportamento? Em B. F. Skinner (Org.), Questões recentes na Análise comportamental (pp. 83-99; A. L. Neri, Trad.). São Paulo: Papirus. (Trabalho original publicado em 1989)

Teixeira, F. C. (2006). Processos comportamentais constituintes de interações profissionais de professores e de alunos com jovens com Síndrome de Down no sistema das organizações de ensino regular (Dissertação de Mestrado). Programa de Pós-Graduação em Psicologia. Universidade Federal de Santa Catarina, Florianópolis, SC.

Tosi, P. C. S. (2005). Expectativas de responsáveis por setores de recursos humanos em relação à atuação dos psicólogos em organizações (Dissertação de mestrado). Programa de Pós-Graduação em Psicologia. Universidade Federal de Santa Catarina, Florianópolis, SC.

Viecili, J. (2005). Formação em Psicologia: Relações entre formação básica, ênfases curriculares, diretrizes curriculares e campo de atuação profissional (Projeto de qualificação para doutoramento). Universidade Federal de Santa Catarina, Florianópolis, SC.

\section{Informações do Artigo}

\section{Histórico do artigo:}

Submetido em: 11/02/2013

Primeira decisão editorial: 11/12/2013

Segunda decisão editorial: 28/12/2013

Aceito em: 17/01/2014 